\title{
Discontinuation among University Students in Southern Thailand
}

\author{
Ruthaychonnee Sittichai \\ Unit for School and Family Studies, Department of Psychology \\ Goldsmiths, University of London, New Cross London SE14 6NW, England \\ Tel: 44-20-7919-7594Ｅ-mail: pss02rs@gold.ac.uk
}

Phattrawan Tongkumchum and Nittaya McNeil

Department of Mathematics and Computer Science

Prince of Songkla University 181 Jaroen Pradit Road, Pattani 94000, Thailand

Tel: 66-73-313-929Ｅ-mail: tphattra@bunga.pn.psu.ac.th; nittaya@bunga.pn.psu.ac.th

The research is financed by the Commission on Higher Education of Thailand

\begin{abstract}
This study uses a statistical model to account for the pattern of discontinuation of university study at Pattani campus of Prince of Songkla University (PSU) in southern Thailand. University records for 11,408 bachelor degree students enrolled between 1999 and 2006 were used. Discontinuation rates were analyzed by using a logistic regression model to determine the joint effects of year of admission, duration of study, faculty, and religion-gender group on discontinuation. The annual average discontinuation rate over the eight year period was $5.3 \%$. The students discontinued most in their first or second year of study. These rates were substantially higher for students entering after 2003, possibly due to demographic changes in the intake.
\end{abstract}

Keywords: University discontinuation, Southern Thailand, Logistic regression

\section{Introduction}

University discontinuation is a global academic problem. This drop-out is influenced by many factors related to both the individual and their social environment. Using sociological concepts of integration Tinto (1975) developed a theory of student retention explaining to some extent why university students discontinue, and many studies of this question have followed. In an early study Johnes \& Taylor (1989) found that the non-completion rate of university students differed substantially between UK universities and that inter-university variation in discontinuation rates could be explained by three factors: the scholastic ability of a university's new entrants, the subject mix of the university, and the proportion of students accommodated in a hall of residence. Thomas (2002) argued that greater diversity leads to an increase in student drop-out. Another study in the UK found that the causes of drop-out are the extent of prior academic preparedness and the social integration at university (Smith \& Naylor, 2001). A study in Italy by Di Pietro (2004) examined factors underlying enrollment and discontinuation decisions using a bivariate statistical model. Montmarquette et al (2001) also used a probability model to examine factors associated with university discontinuation. A US study by Barefoot (2004) concluded that factors related to the classroom situation, student persistence and the way instruction was designed were associated with discontinuation.

There are few previous studies about factors influencing university drop-out in Thailand and none fully reported in English apart from a preliminary study by the present authors (Sittichai et al, 2008), although several studies have addressed discontinuation in vocational colleges. Those concerned with determining underlying causes based on questionnaires and interviews generally find that the main reasons for discontinuation are personal factors such as lack of finance, health problems, lack of basic knowledge, poor time management, and college factors including strict rules, instructor or counselor conflict, family factors such as lack of parental guidance or conflict with home duties, and social factors including conflict with friends, differences in social strata, and lifestyle conflict.

Our study is based on data routinely collected by the Registrar's Office for students enrolled at Pattani Campus of Prince of Songkla University (PSU) in Southern Thailand from 1999-2006. The objective of this study was not to 
investigate the reasons why the students discontinued, but simply to model the probability that a student discontinued study after being enrolled for a given number of years as a function of demographic variables, namely, the gender, religion, admission year, and faculty of enrollment of the student. Prince of Songkla University is the major university in Southern Thailand, one of the four geographical regions in Thailand with a population of approximately 8 million at the 2000 Census, and was the first in the region, established in 1966 in Pattani province, The university now has four additional campuses in Songkla, Phuket, Surat Thani, and Trang provinces, the major one being in Hat Yai City in Songkla. Pattani is located near the border with Malaysia to the south, and approximately 1000 kilometers south of Bangkok. The population in Pattani and the other two southernmost provinces from which Pattani campus draws its students is predominately Muslim (close to $80 \%$ according to the National Statistical Office, 2000). By 1989 Pattani Campus had four faculties (Education, Humanities \& Social Science, Science \& Technology, together with the College of Islamic Studies). Further faculties were added in 2002.

\section{Methods}

The data comprised all students who enrolled to commence the normal four-year bachelor degree in one of the four original faculties, over the eight-year period from 1999 until 2006 inclusive. There were 11,408 students who were admitted to four-year bachelor degree programs and commenced study between 1 June 1999 and 31 October 2006. The study followed them up until 31 March 2008. Normally students enroll early in June for study in two 16-week semesters commencing in June and November, respectively.

Discontinuation, due either to voluntary departure by the student or retirement of the student by the University due to their lack of academic achievement, was defined as the binary outcome variable of interest. Students who departed or changed their enrollment for any other reason, such as graduation, still studying at 31 March 2008, death, or transfer to another program at PSU Pattani necessitating a change of their student number (and thus absence of further information about their status in the University's computerized enrollment database) were treated as censored data.

The factors considered as determinants of the outcome were (a) gender, (b) religion (Muslim or other), (c) faculty (four categories), (d) admission year (eight categories defined as from 1 April until 31 March of the following year), (e) study year (five categories: first, second, third, fourth, or later year).

Logistic regression (Hosmer \& Lemeshow, 2000; Kleinbaum \& Klein, 2002; Venables \& Ripley, 2002) was then used to estimate the probability of the outcome as a function of two factors. The first factor was taken as the combination of admission year and study year, giving 34 levels corresponding to five levels for each of the first five admission years, and, since information was not available beyond 31 March 2008, four, three and two levels, respectively, corresponding to admissions in 2004, 2005 and 2006. The second factor was taken as the combination of gender, religion and faculty, giving 14 levels due to the fact that no non-Muslim students were admitted to the College of Islamic Studies. The proportion pij of these outcomes in level $i$ of the first factor and level $j$ of the second factor was thus expressed as

$$
\ln \frac{p_{i j}}{1-p_{i j}}=\mu+\alpha_{i}+\beta_{j}
$$

To avoid over-specification of the parameters, the coefficients were constrained to have weighted means equal to 0 based on adjusted prevalences. To calculate the adjusted prevalence $p_{i \bullet}$ for category i of the first factor, the term $\beta \mathrm{j}$ in equation (1) was replaced by a constant $\beta 0$, chosen to make the sum of the expected number of outcomes equal to the sum of the observed number, that is,

$$
\sum_{i=1}^{m} p_{i} n_{i}=\sum_{i=1}^{m} p_{i} n_{i}
$$

ni being the sample size in category $i$. The constant $\beta 0$ was computed $\not \operatorname{sing}$ a Newton-Raphson iterative procedure with Marquardt damping. Similarly, to calculate the adjusted prevalence ${ }_{\bullet j}$ for category $\mathrm{j}$ of the second factor, the term $\alpha i$ in (1) was replaced by a constant $\alpha 0$, again chosen to ensure that the sum of the expected number of outcomes equaled the total observed. Standard errors based on weighted sum contrasts (as described in Venables \& Ripley, 2002, Chapter 6) using weights proportional to the sample sizes for each factor level were used to compute standard errors for the estimated prevalences.

The statistical analysis was performed using R (R Development Core Team, 2008). 


\section{Results}

For the preliminary study, we looked at the students who enrolled from 1 June 1999 to 31 October 2003 where the data were last updated at 31 March 2005. It was found that the overall discontinuation rate per student over the five year period was $12 \%$, with the Faculty of Science and Technology having a higher discontinuation rate than the other faculties, particularly for students admitted in 1999. The discontinuation rates were higher for students entering after 2001, with Muslim students having lower drop-out rate than other students (Sittichai, Tongkumchum, \& McNeil, 2008).

Table 1 shows the total numbers of students admitted by year of admission, faculty and religion-gender group during 1999-2006. Over this eight-year period several major changes occurred in the enrollment pattern. The number of students enrolling in four-year bachelor degree programs in the four faculties increased almost by a factor of two between 1999 and 2002 and then decreased slightly for the next two years before dropping substantially in 2006. The corresponding percentage of Muslim students enrolling increased by a much greater factor from just $22.6 \%$ in 1999 to $53.3 \%$ in 2004 with a further jump to $75 \%$ in 2005 , and level off to $77.3 \%$ in 2006 , which is close to the percentage of Muslim people in the region surrounding the campus. Despite this increase in Muslim enrollment the percentage of students admitted to the College of Islamic Studies decreased from a maximum of $20.5 \%$ in 2004 back to just $9.2 \%$ in 2006, approximately the same as it was in 1999. The corresponding percentage of students admitted to the Faculty of Education also decreased substantially from close to $30 \%$ in the period $1999-2003$ to less than $12 \%$ in the following three years.

In contrast, the overall percentage of women students enrolling remained constant at just under $75 \%$ during the whole period.

Table 2 shows the numbers of students discontinuing before 31 March 2008 from 1999 to 2006 by year of admission, faculty and religion-gender group. There were 2,311 students who discontinued during this period $(20.3 \%)$.

Figure 1 shows a plot of adjusted prevalences for each of the two factors with $95 \%$ confidence intervals, after fitting a logistic regression model, using the data in Tables 1 and 2. We fitted the model to the grouped data obtained by taking every combination of the two determinants to obtain $476(34 \times 14)$ cells, in each of which the number of discontinuations is given in Table 2 and the corresponding number at risk is computed by subtracting the number of discontinuations and censored events in preceding years of study from the number of students admitted. The fitted model gave a residual deviance of 675.25 with 429 degrees of freedom. The left panel of Figure 2 shows a plot of the observed number of discontinuations in each cell versus the expected number given by the model, while the right panel shows a plot of the deviance residuals versus the normal quantiles, where two outliers are visible. These outliers correspond to (1) 69 non-Muslim women who enrolled in the Faculty of Science and Technology in 1999 where 23 discontinued in their first year of study, and (2) 16 (Muslim) men who enrolled in the College of Islamic Studies in 2005 where four discontinued in their second year of study. Otherwise the fit of the model appears to be satisfactory.

The logistic regression model indicated that each of the two factors, the admission year \& study year combination and the faculty-gender-religion combination, were strongly associated with discontinuation. The analysis of variance gave reductions in deviance of 1492.78 (33 degrees of freedom) for admission year \& study year and 374.00 (13 degrees of freedom) for faculty-religion-religion.

Figure 1 clearly indicates that the discontinuation pattern remained much the same over the first four admission years from 1999 to 2002, with most discontinuations occurring in the first and second years of study. But in the following four years the pattern changed substantially, first with drop-outs doubling in the students' second year of study starting in 2003, next with an increase in the first-year drop-out rate commencing in 2004, and finally with students dropping out in their third year of study in 2005 . However, some of the third-year drop out increase in 2005 can be attributed to the fact that Thai government provided a large number of scholarships and career position for nursing studies in 2006, and 66 the students studying at PSU Pattani decided to resign in order to take up this opportunity.

\section{Discussion}

With respect to the pattern of enrollment, the major finding of interest from our study was the rapid increase in the proportion of Muslim students entering Pattani campus of PSU from a 23\% minority in 1999 to a 77\% majority in 2006 (see Table 1). During the first six years of this period the percentage of Muslim students enrolling in the College of Islamic Studies was fairly constant, averaging $42 \%$ and ranging from $35 \%$ to $52 \%$. One could conclude that these students, who mostly came from families with little or no tradition of university education, were attracted to a faculty where they felt at home and could succeed with their studies. However, in 2005 the proportion of Muslim students entering the College of Islamic Studies dropped to $24 \%$, and by 2006 it had decreased further to just $12 \%$. A possible reason for this decrease is that the students found that the education they received from the Islamic College did not provide them with the qualifications needed to work in Thailand, a country with only a small overall proportion of Muslims, who mostly reside in southern Thailand where employment opportunities for university graduates remain extremely limited. 
The second major finding of interest is that despite substantial changes in both the size and the pattern of enrollment at PSU Pattani the proportion of women students remained constant at just under $75 \%$. This could be due to lack of employment opportunities for university graduates in the southernmost provinces, where the economy is largely agricultural and male bread-winners travel to Malaysia to find skilled work.

The other features of the enrollment pattern during 1999-2006 were the overall decrease in enrollment after 2002 culminating in a substantial decrease in 2006. However, these decreases were largely due to two factors. First, new faculties of Communication Science, Fine and Applied Arts, and Political Science were established at PSU Pattani after 2002, and these attracted students away from the original four faculties. Second, in 2004 the Faculty of Education introduced a 5-year bachelor degree program for training professional teacher, replacing their 4-year teacher training degree, with the 4-year degree reserved for students majoring in Psychology, Education Evaluation and Research or Educational Technology.

Turning to the pattern of discontinuation, the drop-out rate in the Faculty of Science and Technology was nearly double that for the other faculties. Higher discontinuation rates among science majors have been observed elsewhere in Thailand. Rincome (2002) reported that the highest discontinuation rate among students at Chiang Mai University was in its Faculty of Science. Various reasons have been put forward by academic staff at PSU for this problem, including lack of adequate preparation among students coming from local high schools, particularly those where religion is an important component of the curriculum. However, our preliminary study (Sittichai et al, 2008) found no evidence of differences in drop-out rates between religious and public high schools. Another possible explanation is the fact that, in common with other universities in Thailand and in contrast to the current practice in most western countries, students majoring in science disciplines at PSU are still required to undertake foundation units in basic science including Physics, Chemistry, Biology and Mathematics, irrespective of their chosen science major. Further study on this question is needed.

Among the four demographic groups, non-Muslim males had the highest rate of discontinuation. In their UK study Naylor \& Smith (2001) found that males had higher drop-out rates than females.

Our finding that students tended to discontinue at a greater rate during the first two years of their study is consistent with results reported by Rincome (2002) in her study at Chiang Mai University, and by Yorke (1997) and Thomas (2002) for British students.

The last and possibly most important result from our study was the substantial increasing trend in the drop-out rate in the latter four-year period. Clearly, further study is needed, particularly qualitative research based on interviews with students to establish why this is happening, and particularly to focus on the factors underlying students' satisfaction and dissatisfaction with their studies.

\section{Acknowledgement}

We are grateful for Professor Don McNeil for his helpful advice and suggestions. The study is granted by the Commission on Higher Education of Thailand.

\section{References}

Barefoot, B. (2004). Higher education's revolving door: confronting the problem of student drop out in US colleges and universities. Opening Learning: the Journal of Open and Distance Learning, 19(1), 9-18.

Giorgio, D. (2004). The determinants of university dropout in Italy: a bivariate probability model with sample selection. Applied Economics Letters, 11 187-191.

Hosmer, D. W. \& Lemeshow, S. (2000). Applied Logistic Regression (2 ed.). New York: John Wiley \& Sons.

Johnes, J. \& Taylor, J. (1989). Undergraduate non-completion rates: differences between UK universities. Higher Education, 18, 209-225.

Kleinbaum, D. G. \& Klein, M. (2002). Logistic regression: a self-learning text (2nd ed.). New York: Springer-Verlag.

McNeil, D. (1996). Epidemiological Research Methods. New York : John Wiley \& Sons.

Montmarquette , C., Mahseredjian, S. \& Houle, R (2001 ). The determinants of university dropouts: a bivariate probability model with sample selection Economics of Education Review, $20(5$ ), 475-484.

National Statistical Office, Office of the Prime Minister (2000). The 2000 Population and Housing Census, Pattani Province. Bangkok : National Statistical Office, Office of the Prime Minister.

Rincome, P. (2002). The study of the causes of drop-out of bachelor degree students at Chiang Mai University in 1999-2001. Chiang Mai: Registration Office Chiang Mai University.

Sittichai, R., Tongkumchum, P. \& McNeil, N. (2008 ). Discontinuation among university Students Songklanakarin Journal of Social Science and Humanities, 14(3), 399-408. 
Smith J.P., N. R. A. (2001). Dropping out of university: a statistical analysis of the probability of withdrawal for UK university students Journal of the Royal Statistical Society (A), 164, 389-405.

Team, R. D. C. (2008). $R:$ A language and environment for statistical computing Vienna R Foundation for Statistical Computing.

Thomas, L. (2002 ). Student retention in higher education: the role of institutional habitus. Journal of Educational Policy, 17(4), 423-432.

Tinto, V. (1993). Leaving college: Rethinking the causes and cures of student attrition (2nd ed ed.). Chicago: The University of Chicago Press.

Yorke, M. (1997). Non-completion of undergraduate study: some implications for policy in higher education Journal of Higher Education Policy and Management. 20(2), 189-201. 